This is the accepted version of the following article:

Lima G., Dubal D.P., Rueda-García D., Gómez-Romero P., Huguenin F.. Energy harvesting from neutralization reactions with saline feedback. Electrochimica Acta, (2018). 275. : 145 - . 10.1016/j.electacta.2018.04.075,

which has been published in final form at https://dx.doi.org/10.1016/j.electacta.2018.04.075 (c) https://dx.doi.org/10.1016/j.electacta.2018.04.075. This manuscript version is made available under the CC-BY-NC-ND 4.0 license http://creativecommons.org/licenses/by-nc-nd/4.0/ 


\section{Energy Harvesting from Neutralization Reactions with Saline Feedback}

Gilberto Lima ${ }^{1}$, Deepak P. Dubal ${ }^{2}$, Daniel R. García ${ }^{2}$, Pedro Gómez-Romero ${ }^{2}$, and Fritz Huguenin ${ }^{1 *}$

1- Departamento de Química, Faculdade de Filosofia, Ciências e Letras de Ribeirão Preto Universidade de São Paulo, 14040-901 Ribeirão Preto (SP), Brazil

2 - Catalan Institute of Nanoscience and Nanotechnology (ICN2), and The Barcelona Institute of Science and Technology (CSIC-BIST), Campus UAB, Bellaterra, 08193 Barcelona, Spain

*e-mail: fritz@fffclrp.usp.br 


\begin{abstract}
This work proposes an acid-base machine consisting of insertion electrodes for protons and alkaline metal ions placed in electrolytic solutions with different $\mathrm{pH}$ values and alkaline ion concentrations for energy harvesting from a neutralization reaction. We simulate energy harvesting during acid wastewater treatment with base $(\mathrm{KOH})$ by using phosphomolybdic acid and nickel hexacyanoferrate as the negative and positive electrodes, respectively, in aqueous $\mathrm{H}_{2} \mathrm{SO}_{4}$ and $\mathrm{K}_{2} \mathrm{SO}_{4}$ solutions. In this configuration, the machine harvests energy from the partial change in entropy related to proton and potassium ion concentration changes after neutralization reactions and with feedback from the saline solution resulting from neutralization. The potentiodynamic profile of the current indicates alterations in the potential window associated with the electroinsertion processes before and after neutralization. The electrochemical impedance spectroscopy diagrams aid investigation into the practical proton and potassium ion electroinsertion reversibility in acid and neutral media. Based on the charge/discharge curves at $\mathrm{pH}=2$ and $\mathrm{pH}=5.8$, the acid-base machine harvests $21.8 \mathrm{~kJ}$ per mol of electroinserted protons. These results demonstrate that the methodology is viable for sustainable growth - it can harvest energy from wastewater treatment, a practice that can be profitable mainly for the industrial sector, which produces great amounts of wastewater.
\end{abstract}

Keywords: neutralization batteries; acid-base machine; neutralization pseudocapacitors; mixing entropy battery; energy harvesting; CAPMIX. 


\section{INTRODUCTION}

Global warming and the lack of water resources are among the greatest challenges faced by humankind and have stimulated the development of renewable and clean energy sources as well as the design of new strategies to treat wastewater. In this scenario, energy harvesting from wastewater treatment represents a doubly attractive process. Electrochemical systems that can efficiently convert and store energy could be applied in this type of energy harvesting, making the treatment of waste profitable, especially for the industrial sector $[1,2]$.

Brogioli et al. proposed an electrochemical system called capacitive mixing (CapMix), where electrical double-layer capacitors are immersed into diluted and concentrated salt solutions $[3,4]$. This system allows electrical work to be performed from entropy changes associated with the salt gradient [3]. La Mantia et al. replaced capacitors with insertion electrodes, which can also be used to harvest energy from mixing entropy processes associated with the mixture of seawater and river water [5]. These blue-energy devices can harvest 1.6 and $2.5 \mathrm{~kJ}$ from saline gradient per cubic decimeter of fresh water, respectively.

In previous studies, we proposed acid-base machines (neutralization batteries or pseudocapacitors) to achieve electrical work from acid or base wastewater neutralization [1, 2]. These devices operate between acid and basic reservoirs and use specific insertion/deinsertion electrodes that are selective for protons (Figure 1a) [1]. Addition of reagents from the reservoirs to neutralize acid or base solutions enables energy harvesting: the partial entropy associated with the proton concentration in the electrolyte solution varies and leads to a complete electrochemical cycle where the proton (or hydroxyl ion) electroinsertion process takes place in one of the electrodes, in acid (or alkaline) medium. Electroinsertion is followed by addition of base (or acid), proton (or hydroxyl ion) electrodeinsertion from the 
electrode to the alkaline (or acid) solution, and saline solution discharge into a suitable medium. A spontaneous process and another non-spontaneous process (achieved by using a secondary battery coupled to an acid-base machine, for instance) occur during this electrochemical cycle. The change in the Gibbs free energy associated with the spontaneous process is higher in modulus than the change in the Gibbs free energy in the case of the nonspontaneous process. Consequently, energy is transferred and harvested (in a coupled secondary battery, for instance) after the electrochemical cycle, and acid (or alkaline) solutions are neutralized.

The charge/discharge curve profiles (Figure 1b) obtained for acid-base machine resemble the charge/discharge curve profiles of conventional secondary batteries. However, the voltage associated with the discharge step (spontaneous process) is greater than the voltage associated with the charge step (non-spontaneous process) because at least one of the electrodes is selective for only one of the ions (protons) present in the electrolytic solution, and the ion concentration changes after the neutralization reaction. Thus, acid-base machines produce electrical work equivalent to the area between the charge/discharge curves $[3,5]$. In contrast, the area between the curves corresponds to dissipated heat in the case of batteries that operate under a closed system, in which the electrolyte concentration remains the same during the charge/discharge processes.

For application in acid-base machines, insertion electrodes must (i) be electroactive; (ii) have a structure that allows for selective ion insertion/deinsertion, so as to elicit a change in potential after neutralization; (iii) display high charge capacity to maximize the energy harvested per cycle and per volume of neutralized solution; (iv) possess high conductivity to reduce the ohmic drop; (v) be inexpensive; and (vi) show low toxicity. In addition, (vii) the ionic insertion/deinsertion process must present low practical and chemical irreversibility; 
(viii) minimum modifications to the electrode structure should increase machine cyclability; and (ix) the inserted ions must be highly mobile, to reduce the overpotentials associated with mass transport.
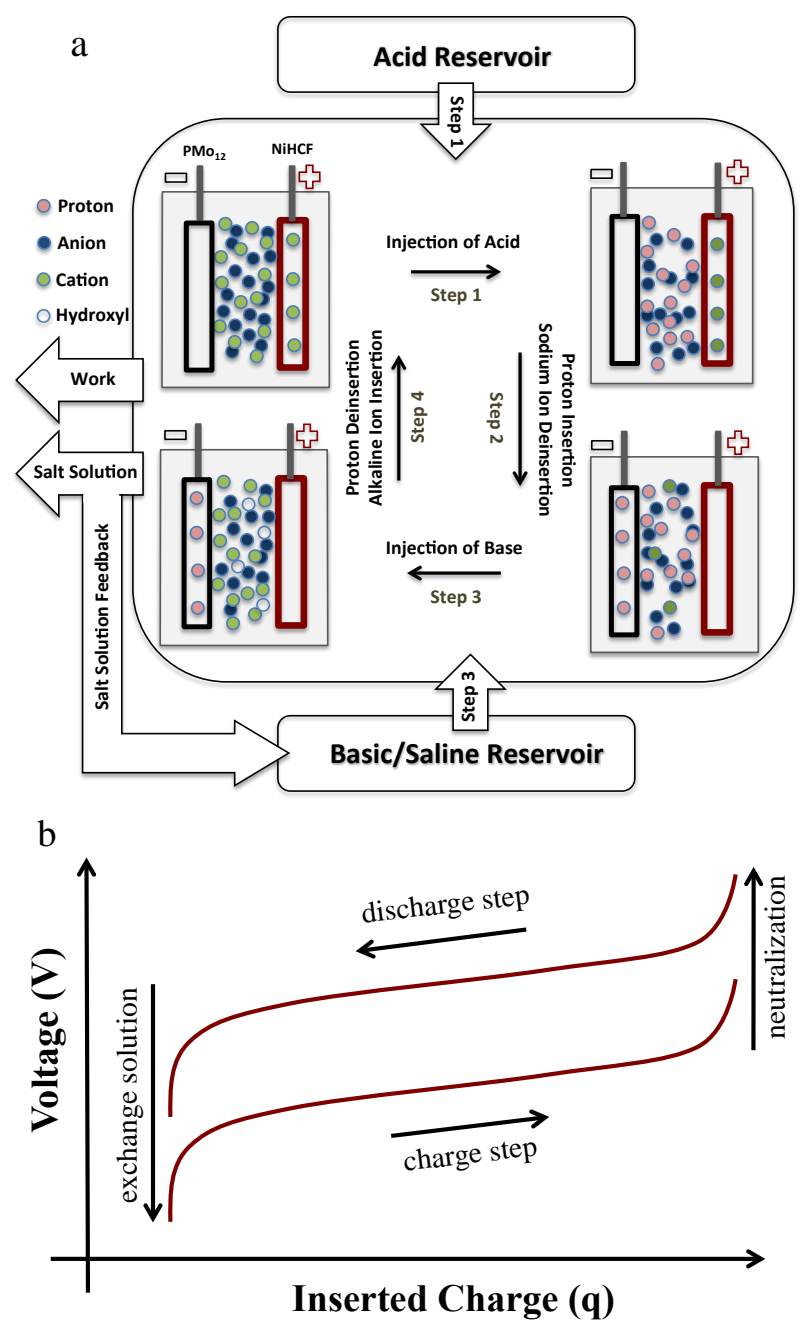

Figure 1 - (a) Acid-base machine working principle: addition of acid into the machine (step $1)$; insertion of protons in the negative electrode and deinsertion of alkaline ions from the positive electrode (step 2); addition of base and salt to the machine (step 3); deinsertion of protons from the negative electrode and insertion of alkaline ions in the positive electrode (step 4); and discharge of the resulting saline solution into a suitable environment or injection of the resulting saline solution in the base reservoir. (b) Schematic profile of the 
charge/discharge curves obtained for acid-base machines. The line integral corresponds to the energy harvested after the electrochemical cycle.

The electrode consisting of phosphomolybdic acid (PMo12) is a good insertion electrode: it is highly conductive for protons and has high insertion/deinsertion rate [6]. Protons are preferentially inserted in $\mathrm{PMo}_{12}$ according to the reaction below. Electroinsertion of two protons compensates injection of two electrons into the cluster LUMO [7]:

$$
\begin{aligned}
& \mathrm{PMo}_{12} \mathrm{O}_{40}-3+2 \mathrm{e}^{-}+2 \mathrm{H}^{+} \rightarrow \mathrm{H}_{2} \mathrm{PMo}_{10}{ }^{\mathrm{VI}} \mathrm{Mo}_{2}{ }^{\mathrm{V}} \mathrm{O}_{40}{ }^{-3} \\
& \mathrm{H}_{2} \mathrm{PMo}_{10}{ }^{\mathrm{VI}} \mathrm{Mo}_{2}{ }^{\mathrm{V}} \mathrm{O}_{40}{ }^{-3}+2 \mathrm{e}^{-}+2 \mathrm{H}^{+} \rightarrow \mathrm{H}_{4} \mathrm{PMo}_{8}{ }^{\mathrm{VI}} \mathrm{Mo}_{4}{ }^{\mathrm{V}} \mathrm{O}_{40}{ }^{-3} \\
& \mathrm{H}_{4} \mathrm{PMo}_{8}{ }^{\mathrm{VI}} \mathrm{Mo}_{4}{ }^{\mathrm{V}} \mathrm{O}_{40}{ }^{-3}+2 \mathrm{e}^{-}+2 \mathrm{H}^{+} \rightarrow \mathrm{H}_{6} \mathrm{PMo}_{6}{ }^{\mathrm{VI}} \mathrm{Mo}_{6}{ }^{\mathrm{V}} \mathrm{O}_{40}{ }^{-3}
\end{aligned}
$$

Regarding these machines, finding electrodes that are selective for anions remains a difficulty. Furthermore, acidic solution neutralization does not alter the anion concentration, so anions do not contribute to increasing the energy storage capacity. To avoid the use of anion-selective electrodes, here we propose the use of alkaline ion insertion/deinsertion electrodes - the proton and alkaline ion concentrations should change during acid solution neutralization with alkaline metal hydroxides and/or during acid solution dilution with seawater, or even with the use of saline solution resulting from the neutralization reactions of previous cycles (Figure 1a).

A family of materials known as Prussian blue analogues has been widely studied as intercalation electrode for alkali ions [8-12]. In the presence of an appropriate electrolyte, these intercalation materials have long life cycle, high intercalation rate, and high charge storage capacity, meeting the requirements for use in acid-base machines. Their chemical formula is $\mathrm{A}_{\mathrm{x}} \mathrm{P}_{\mathrm{y}}\left[\mathrm{R}(\mathrm{CN})_{6}\right]_{\mathrm{z}} \cdot \mathrm{wH}_{2} \mathrm{O}$, where $\mathrm{A}$ is an alkali cation, $\mathrm{R}$ is a transition metal ion, and $\mathrm{P}$ 
are transition metals octahedrally coordinated to nitrogen atoms of hexacyanometallate groups. In this study, we employ nickel hexacyanoferrate (NiHCF, whose chemical formula is $\left.\mathrm{KNiFe}^{\mathrm{III}}(\mathrm{CN})_{6} \cdot \mathrm{wH}_{2} \mathrm{O}\right)$ as insertion electrode because it displays long life cycle; high power, energy density, and coulombic efficiency; and preference for alkaline metal ion [13].

By using $\mathrm{KOH}$ to neutralize an acid solution in the acid-base machine where $\mathrm{PMo}_{12}$ and NiHCF are the negative $\left(\mathrm{M}_{2}\right)$ and positive $\left(\mathrm{M}_{1}\right)$ electrodes, respectively, we can obtain the energy harvested from the variation in the partial entropy associated with changes in the proton and potassium ion concentrations. According to the non-spontaneous reactions in acid medium,

$\mathrm{PMo}_{12} \mathrm{O}_{40}{ }^{-3}+\mathrm{xe}^{-}+\mathrm{xH}^{+} \rightarrow \mathrm{H}_{\mathrm{x}} \mathrm{PMo}_{10}{ }^{\mathrm{VI}} \mathrm{Mo}_{2}{ }^{\mathrm{V}} \mathrm{O}_{40}{ }^{-3} \quad$ (negative electrode)

$\mathrm{K}_{(1+\mathrm{x})} \mathrm{Ni}\left[\mathrm{Fe}^{\mathrm{II}}(\mathrm{CN})_{6}\right]_{\mathrm{x}}\left[\mathrm{Fe}^{\mathrm{III}}(\mathrm{CN})_{6}\right]_{1-\mathrm{x}} \rightarrow \mathrm{KNiFe}^{\mathrm{III}}(\mathrm{CN})_{6}+\mathrm{xK}^{+}+\mathrm{xe}^{-}$(positive electrode)

and to the spontaneous reactions in neutral (or less acid) medium containing high potassium ion concentration,

$$
\begin{aligned}
& \mathrm{H}_{\mathrm{x}} \mathrm{PMo}_{10}{ }^{\mathrm{VI}} \mathrm{Mo}_{2}{ }^{\mathrm{V}} \mathrm{O}_{40}{ }^{-3} \rightarrow \mathrm{PMo}_{12} \mathrm{O}_{40}{ }^{-3}+\mathrm{xe}^{-}+\mathrm{xH}^{+} \quad \text { (negative electrode) }
\end{aligned}
$$

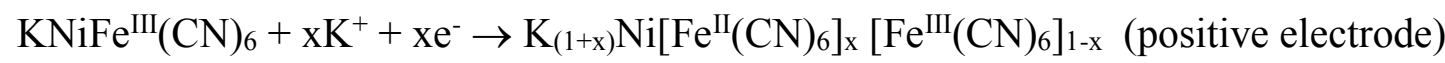

the voltage variation $(\Delta \mathrm{V})$ after neutralization can be determined by the overpotentials and the voltage variation at the equilibrium state $\left(\Delta \mathrm{V}_{\text {eq }}\right)$ in the acid and neutral medium, which is obtained from the equality of the electrochemical potentials of the chemical species involved in Equations 4-7:

$$
\Delta \mathrm{V}=\Delta \mathrm{V}_{\text {eq }}-\left(\eta_{\text {discharge }}+\eta_{\text {charge }}\right)=\quad \frac{\mathrm{RT}}{\mathrm{F}} \ln \left(\frac{\mathrm{a}_{\mathrm{M}_{1}}^{\mathrm{n}}}{\mathrm{a}_{\mathrm{KM}_{1}}^{\mathrm{n}}} \frac{\mathrm{a}_{\mathrm{M}_{2} \mathrm{H}}^{\mathrm{n}}}{\mathrm{a}_{\mathrm{M}_{2}}^{\mathrm{n}}} \frac{\mathrm{a}_{\mathrm{K}^{+}}^{\mathrm{n}}}{\mathrm{a}_{\mathrm{H}^{+}}^{\mathrm{n}}} /\right.
$$


$\left.\frac{\mathrm{a}_{\mathrm{M}_{1}}^{\mathrm{a}}}{\mathrm{a}_{\mathrm{KM}}^{\mathrm{a}}} \frac{\mathrm{a}_{\mathrm{M}_{2} \mathrm{H}}^{\mathrm{a}}}{\mathrm{a}_{\mathrm{M}_{2}}^{\mathrm{a}}} \frac{\mathrm{a}_{\mathrm{K}^{+}}^{\mathrm{a}}}{\mathrm{a}_{\mathrm{H}^{+}}^{\mathrm{a}}}\right)-\left(\eta_{\text {discharge }}+\eta_{\text {charge }}\right)$

where $\mathrm{R}$ is the ideal gas constant, $\mathrm{T}$ is the absolute temperature, $\mathrm{F}$ is the Faraday constant, and $\eta_{\text {charge }}$ and $\eta_{\text {discharge }}$ are the overpotentials associated with charge and discharge, respectively. The $a_{M_{1}}, a_{K_{1}}, a_{M_{2}}, a_{M_{2} H}, a_{H^{+}}$and $a_{K^{+}}$terms are the activities of the $M_{1}$ electrode, the reduced $M_{1}$ electrode, the $M_{2}$ electrode, the reduced $M_{2}$ electrode, the proton, and the potassium ion, respectively. The superscripts " $a$ " and " $n$ " refer to activity in acid and neutral (or less acid) medium, respectively. Given that the proton and potassium ion activity decreases and increases after neutralization, respectively, the voltage at equilibrium increases. Based on this idea, we have investigated $\mathrm{PMo}_{12}$ and $\mathrm{NiHCF}$ electrodes in acid and less acid medium under several currents, concentrations, and charge/discharge cycles, aiming to obtain experimental conditions to maximize the harvested energy as well performing a proof-ofconcept to evaluate the machine proposed here.

\section{EXPERIMENTAL}

The NiHCF material was synthesized by the co-precipitation method [13]. To this end, $100 \mathrm{~mL}$ of a solution containing $\mathrm{Ni}\left(\mathrm{NO}_{3}\right)_{2}$ (Sigma-Aldrich) at $27.17 \mathrm{mM}$ and $100 \mathrm{~mL}$ of a $\mathrm{K}_{3} \mathrm{Fe}(\mathrm{CN})_{6}$ (Acros Organics) $25 \mathrm{mM}$ solution were simultaneously and slowly added to 200 $\mathrm{mL}$ of deionized water to a constant stoichiometric ratio. These precursors were allowed to react in water, and the precipitate was filtered-off, washed with water, and dried at $120{ }^{\circ} \mathrm{C}$ under vacuum.

The NiHCF electrode was prepared by mixing the corresponding solid with carbon black (Super $\mathrm{P}^{\circledR}$ Conductive, 99+ \%) and polyvinylidene fluoride (PVDF, Tecaflon) at 80:10:10 ratio. The mixture was dispersed in 1-methyl-2-pyrrolidinone $(0.3 \mathrm{~mL}$ for every 100 
$\mathrm{mg}$ of the mixture of solids, Sigma-Aldrich). The dispersion was then agitated for $12 \mathrm{~h}$ and coated on carbon cloth. The electrode was dried at $80{ }^{\circ} \mathrm{C}$ for one day. The geometrical area was $1 \mathrm{~cm}^{2}$.

The $\mathrm{PMo}_{12}$ electrode was prepared by combining $\mathrm{H}_{3} \mathrm{PMo}_{12} \mathrm{O}_{40} \cdot 6 \mathrm{H}_{2} \mathrm{O}$ (Sigma-Aldrich), carbon black (Super $\mathrm{P}^{\circledR}$ Conductive, 99+ \%), and polyvinylidene fluoride (PVDF, Tecaflon) at 60:25:15 ratio. Carbon black and $\mathrm{H}_{3} \mathrm{PMo}_{12} \mathrm{O}_{40} \cdot 6 \mathrm{H}_{2} \mathrm{O}$ were added to $3 \mathrm{~mL}$ of isopropyl alcohol, which was followed by sonication for 30 min and stirring for one day. Finally, PVDF was added to this dispersion and stirred for $2 \mathrm{~h}$. The resulting dispersion was coated on carbon cloth and dried at $80{ }^{\circ} \mathrm{C}$ for one day. The geometrical area was $1 \mathrm{~cm}^{2}$.

Morphological examination of the $\mathrm{PMo}_{12}$ and $\mathrm{NiHCF}$ electrodes was performed on a scanning electron microscope (SEM/Zeiss mod. EVO 50/Cambridge UK). Powder NiHCF was characterized by X-ray diffraction (XRD) measurements, recorded on a Siemens D5005 diffractometer with monochromatic $\mathrm{Cu}-\mathrm{K}_{\mathrm{a}}$ radiation. The diffraction peaks at $2 \theta 15.18^{\circ}$, $17.50^{\circ}, 28.82^{\circ}, 35.34^{\circ}, 39.62^{\circ}, 43.54^{\circ}, 46.36^{\circ}, 50.74^{\circ}, 54.16^{\circ}$, and $57.30^{\circ}$ were due to the (111), (200), (220), (400), (420), (422), (511), (440), (600), and (620) planes of the facecentered cubic structure.

The electrochemical experiments were carried out on an Autolab PGSTAT30 potentiostat/galvanostat. A platinum gauze and $\mathrm{Ag} / \mathrm{AgCl}$ in saturated $\mathrm{KCl}$ were used as counter and reference electrodes, respectively. The electrolytic solutions were purged with nitrogen. For the experiment involving variations in proton and potassium ion concentrations, electrolytic $\mathrm{H}_{2} \mathrm{SO}_{4}$ (Sigma-Aldrich), $\mathrm{K}_{2} \mathrm{SO}_{4}$ (Sigma-Aldrich), $\mathrm{CH}_{3} \mathrm{COOH}$ (Sigma-Aldrich), and $\mathrm{CH}_{3} \mathrm{COOK}$ (Sigma-Aldrich) solutions were exchanged by means of a four-channel peristaltic pump model BT100-1F acquired from LongerPump. The ac electrochemical impedance spectroscopy was carried out between $100 \mathrm{kHz}$ and $100 \mathrm{mHz}$; the ac amplitude 
was $5 \mathrm{mV}$. The Mapple software was used to fit the Nyquist diagrams.

\section{RESULTS AND DISCUSSION}

To investigate the performance of the acid-base machine, we first performed electrochemical studies on the PMo 12 and $\mathrm{NiHCF}$ electrodes separately. Figure 2a displays the cyclic voltammograms recorded for $\mathrm{PMo}_{12}$ at $\mathrm{pH}=2.0,3.0,4.1,5.1$, and 5.8 at $10 \mathrm{mV} \mathrm{s}^{-1}$. The difference in potential between the peak potentials of redox pairs I and II and between the peak potentials of redox pairs III and IV in the voltammogram obtained at $\mathrm{pH}=2$ is $27 \mathrm{mV}$ and $28 \mathrm{mV}$, respectively. At $\mathrm{pH}=1$, these values are closer to $20 \mathrm{mV}$ (see support information), indicating that the current peaks are not associated with the electroactive species diffusion in solution [14]. In fact, these peaks indicate a maximum proton insertion/deinsertion rate to compensate the charge related to $\mathrm{PMo}_{12}$ reduction/oxidation. Moreover, the potential window changes: the redox pairs arise at less positive potentials at $\mathrm{pH}$ $=5.8$ as compared to $\mathrm{pH}=2$. Figure $2 \mathrm{~b}$ shows the average between the oxidation and reduction peak potentials as a function of $\mathrm{pH}$. On the basis of Nernst's equation, the slope of these curves should be close to $59 \mathrm{mV}$ per logarithmic unit as a result of protons participating in reversible charge transference and fast proton diffusion processes. However, our results83.3 and $74.3 \mathrm{mV}$ per logarithmic unit for the redox pairs I-II and III-IV, respectivelysuggest that protons participate in the charge compensation mechanism $[15,16]$ because the potassium and sulfate ion concentrations $(50 \mathrm{mM})$ remain constant. In the case of acid-base machines, proton participation is necessary to harvest energy from a neutralization process, as mentioned above. 

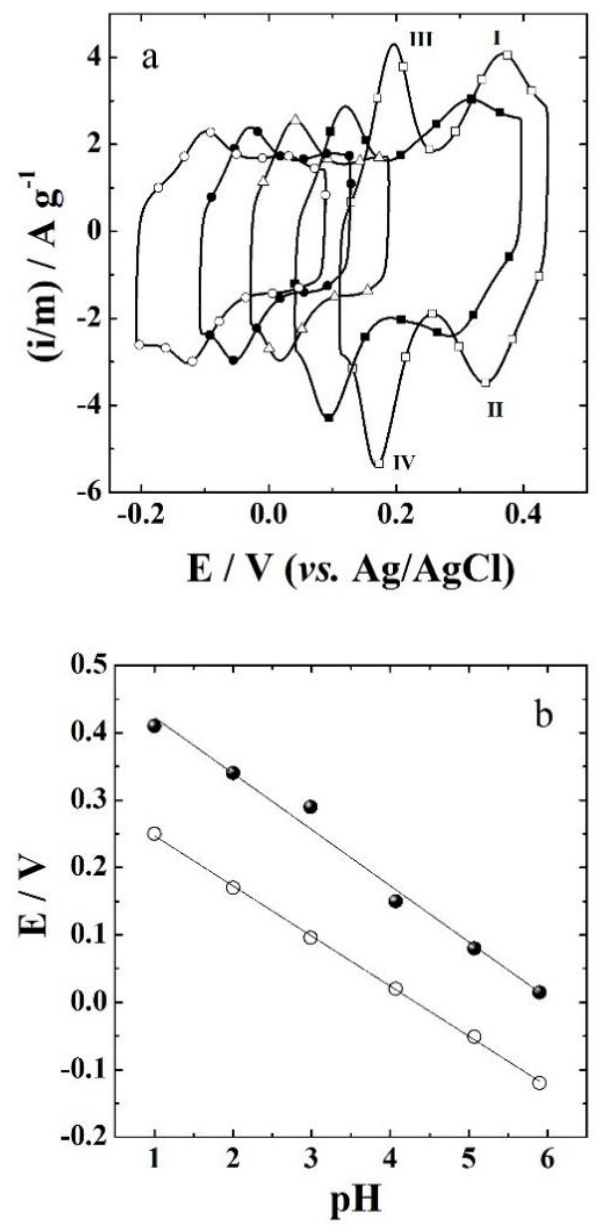

Figure $2-$ (a) $\mathrm{PMo}_{12}$ cyclic voltammograms at $\mathrm{pH}=2.0(\square-), 3(\square-), 4.1(-\Delta-), 5.1$ $(-\bullet-)$, and 5.8 (—- - ) and $\mathrm{K}_{2} \mathrm{SO}_{4} 25 \mathrm{mM}$; (b) Average between the oxidation and reduction peak potentials as a function of $\mathrm{pH}$ associated with the $(\bullet)$ I-II and (०) III-IV redox pairs. $\mathrm{m}=0.107 \mathrm{mg} . \mathrm{v}=10 \mathrm{mV} \mathrm{s}^{-1}$

Figure $3 \mathrm{a}$ illustrates the electroinsertion and electrodeinsertion curves achieved for the $\mathrm{PMo}_{12}$ electrode at $\mathrm{pH}=2$. Based on the mass associated with $\mathrm{PMo}_{12}(0.107 \mathrm{mg})$, the specific capacity changes from $82.3 \mathrm{mAh} \mathrm{g}^{-1}$ (at $10 \mu \mathrm{A}$ or $93.4 \mathrm{~mA} \mathrm{~g}^{-1}$ ) to $54.8 \mathrm{mAh} \mathrm{g}^{-1}$ (at $200 \mu \mathrm{A}$ or $\left.1869.2 \mathrm{~mA} \mathrm{~g}^{-1}\right)$. High currents allow energy conversion from neutralization reactions to occur more rapidly, which is interesting from a practical viewpoint. However, energy harvesting originates from changes in entropy and is not high as compared to other energy sources. The minimum overpotential is important for converting changes in entropy to electrical energy 
after the electrochemical cycle. Moreover, high charge capacities provide large energy harvesting during the electrochemical cycle. When $\mathrm{PMo}_{12}$ is the negative electrode, low currents can decrease the overpotential and increase the charge capacity during the electroinsertion process in more acid medium. Figure $3 \mathrm{~b}$ contains the proton electroinsertion/electrodeinsertion curves obtained for the $\mathrm{PMo}_{12}$ electrode at $\mathrm{pH}=5.8$. Considering our interest in proton electrodeinsertion at this $\mathrm{pH}$ and knowing that no secondary reactions take place during the oxidation process in the investigated potential window, the lowest current $(10 \mu \mathrm{A})$ should reduce the overpotential and increase the charge capacity. This situation calls for low current values to guarantee conversion from entropic energy (associated with change in proton activity) to useful energy after the electrochemical cycle. The specific capacity is $22 \mathrm{mAh} \mathrm{g}^{-1}$ at $93.4 \mathrm{~mA} \mathrm{~g}^{-1}$ and decreases to $14.5 \mathrm{mAh} \mathrm{g}^{-1}$ at $200 \mu \mathrm{A}$, which corresponds to $1869.2 \mathrm{~mA} \mathrm{~g}^{-1}$.

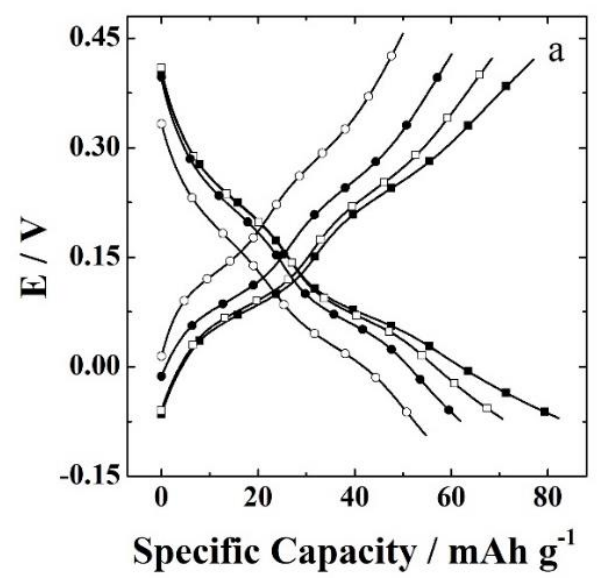




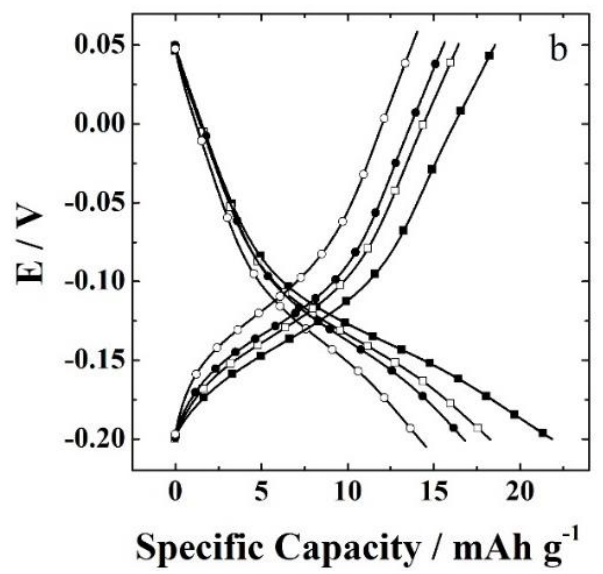

Figure 3 - Electroinsertion and electrodeinsertion curves for the PMo 12 electrode at $(\square-)$ $10 \mu \mathrm{A}$ or $93.4 \mathrm{~mA} \mathrm{~g}^{-1},(-\square-) 20 \mu \mathrm{A}$ or $186.9 \mathrm{~mA} \mathrm{~g}^{-1},(-\bullet) 50 \mu \mathrm{A}$ or $467.3 \mathrm{~mA} \mathrm{~g}^{-1}$, $\left(\right.$ ——) $200 \mu \mathrm{A}$ or $1869.2 \mathrm{~mA} \mathrm{~g}^{-1}$ at (a) $\mathrm{pH}=2$, and (b) $\mathrm{pH}=5.8 . \mathrm{m}=0.107 \mathrm{mg}$.

Figure 4 presents the specific capacity as a function of the number of electroinsertion/electrodeinsertion cycles in electrolytic solution at (a) $\mathrm{pH}=2$ and (b) $\mathrm{pH}=$ 5.8, which changes from $82 \mathrm{mAh} \mathrm{g}^{-1}$ to $45.9 \mathrm{mAh} \mathrm{g}^{-1}$ at $\mathrm{pH}=2$ and from $22.0 \mathrm{mAh} \mathrm{g}^{-1}$ to 16.6 $\mathrm{mAh}^{-1}$ at $\mathrm{pH}=5.8$. On the basis of these data, we also determined the coulombic efficiency between the oxidation and reduction processes. This parameter changes from $78.8 \%$ to $95.0 \%$ and from $84.5 \%$ to $82.5 \%$ between the first and the twentieth cycle at $\mathrm{pH}=2$ and 5.8 , respectively. The difference between the maximum value of coulombic efficiency (100\%) and the values above can be attributed to electrode self-discharge during the oxidation process and/or charge trapping in the electrode after the reduction process, which changes from $22 \%$ to $5 \%$ of total injected charge as a function of the number of cycles. 


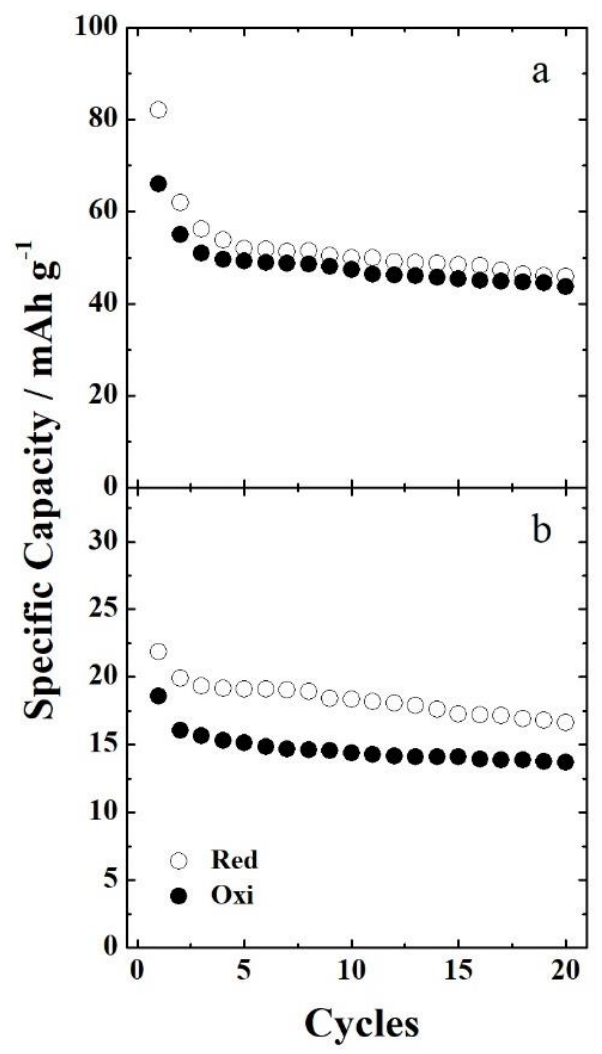

Figure 4 - Cyclability for the $\mathrm{PMo}_{12}$ electrode at (a) $\mathrm{pH}=2$ and (b) $\mathrm{pH}=5.8 . \mathrm{m}=0.107 \mathrm{mg}$ and $\mathrm{i} / \mathrm{m}=93.4 \mathrm{~mA} \mathrm{~g}^{-1}$.

Figure 5a and 5b show the SEM image obtained for the PMo 12 electrode at low and high magnification, respectively. $\mathrm{PMo}_{12}$ clusters with diameter of approximately $50 \mathrm{~nm}$ are agglomerated and distributed together with spherical Super P carbon particles with diameter of approximately $180 \mathrm{~nm}$. We can also observe that the polyoxometallate partially covers the carbon cloth carbon fiber surface, which is used as current collector and electronic conductor. Additionally, these images show that the $\mathrm{PMo}_{12}$ electrode is a rough material in contact with the electrolytic solution, which penetrates into the voids and contributes to ion transport. Given this morphology, we used the porous electrode model to fit the impedance data shown in Figure $6[17,18]$,

$Z=R_{S}+\frac{x_{1} x_{2}}{x_{1}+x_{2}}\left(L+\frac{2 \lambda}{\sinh (L / \lambda)}\right)+\lambda \frac{x_{1}^{2}+x_{2}^{2}}{x_{1}+x_{2}} \operatorname{coth}(L / \lambda)$ 
$x_{2}=\frac{r_{2}}{1+\left(i \omega / \omega_{m}\right)^{p}}$

$\lambda=\left[\zeta /\left(x_{1}+x_{2}\right)\right]^{1 / 2}$

$\zeta=\frac{1}{q_{3}}(i \omega)^{-\beta}$

where $R_{s}$ is the sum of the contact resistance and electrolytic solution resistance; the terms $\mathrm{x}_{1}$ and $\mathrm{x}_{2}$ correspond to impedances per unit length associated with the liquid and solid phase, respectively; the term $r_{2}$ corresponds to resistance per unit length associated with the solid phase, respectively; $\zeta$ is an impedance length related to faradaic currents; the $\beta$ and $\mathrm{p}$ parameter are dimensionless; $\mathrm{q}_{3}$ is a constant; $\mathrm{L}$ is the thickness of the electrode; $\mathrm{i}$ is the imaginary unit; $\omega$ is the angular frequency; and $\omega_{\mathrm{m}}$ is the characteristic frequency. Table 1 lists the values of these parameters, which we used to fit the experimental impedance data.

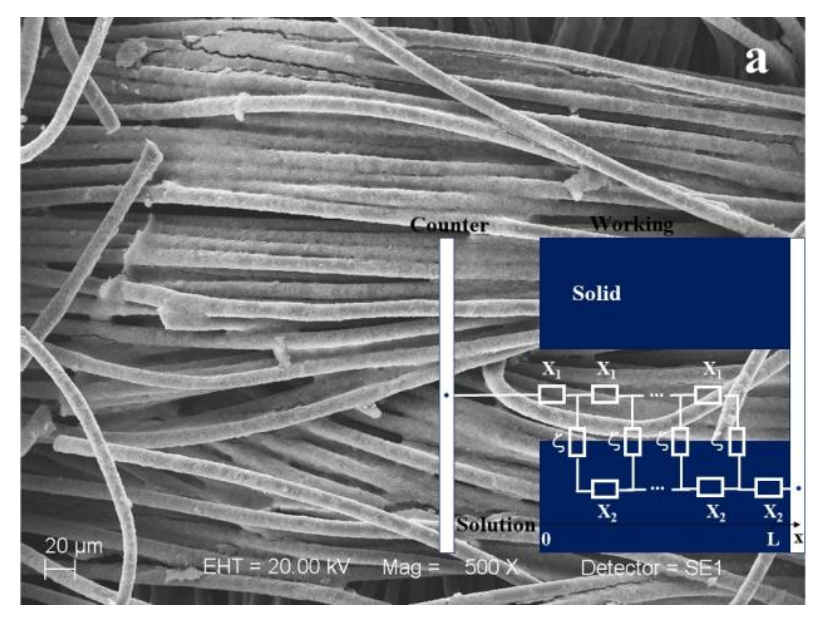




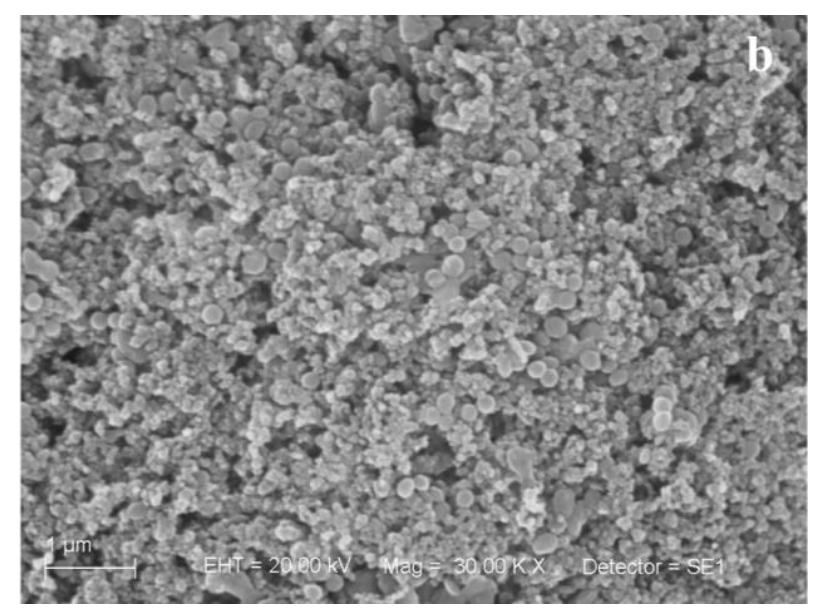

Figure 5-SEM images of the PMo12 electrode at (a) low and (b) high magnification.

Table 1 - Parameters obtained from fitting of the $\mathrm{PMo}_{12}$ electrode electrochemical impedance diagrams.

\begin{tabular}{|c|c|c|c|c|c|c|c|c|c|}
\hline $\mathrm{pH}(\mathrm{E} / \mathrm{V})$ & $\begin{array}{l}\mathrm{R}_{\mathrm{S}} \\
\Omega\end{array}$ & $\begin{array}{c}\mathrm{x}_{1} \\
\mathrm{k} \Omega \mathrm{cm}^{-1}\end{array}$ & $\begin{array}{c}\mathrm{r}_{2} \\
\mathrm{k} \Omega \mathrm{cm}^{-1}\end{array}$ & $\begin{array}{l}\omega_{\mathrm{m}} \\
\mathrm{Hz}\end{array}$ & $\begin{array}{c}\mathrm{L} \\
\mu \mathrm{m}\end{array}$ & $\begin{array}{c}\mathrm{q}_{3} \\
\mathrm{~F} \mathrm{~s}^{\beta-1} \mathrm{~cm}^{-1}\end{array}$ & $\mathrm{p}$ & $\beta$ & $\begin{array}{c}\text { error } \\
\%\end{array}$ \\
\hline $2.0(0.2)$ & 19.2 & 20 & 50 & 1200 & 100 & 295 & 0.95 & 0.81 & 0.04 \\
\hline $5.8(-0.1)$ & 27.0 & 35 & 82 & 600 & 100 & 108 & 0.95 & 0.83 & 0.03 \\
\hline
\end{tabular}

Figure 6 brings the electrochemical impedance diagrams obtained for the PMo 12 electrode (a) at $0.2 \mathrm{~V}$ and $\mathrm{pH}=2$ and (b) at $-0.1 \mathrm{~V}$ and $\mathrm{pH}=5.8$. The $\mathrm{x}_{1}$ values increase from $20 \mathrm{k} \Omega \mathrm{cm}^{-1}$ to $35 \mathrm{k} \Omega \mathrm{cm}^{-1}$ when the solution $\mathrm{pH}$ changes from 2 to 5.8 . Meanwhile, the $\mathrm{r}_{2}$ values vary from $50 \mathrm{k} \Omega \mathrm{cm}^{-1}$ to $82 \mathrm{k} \Omega \mathrm{cm}^{-1}$. These results suggest that the mobility of the charge carriers (proton and electron) decreases slightly in less acid medium. 

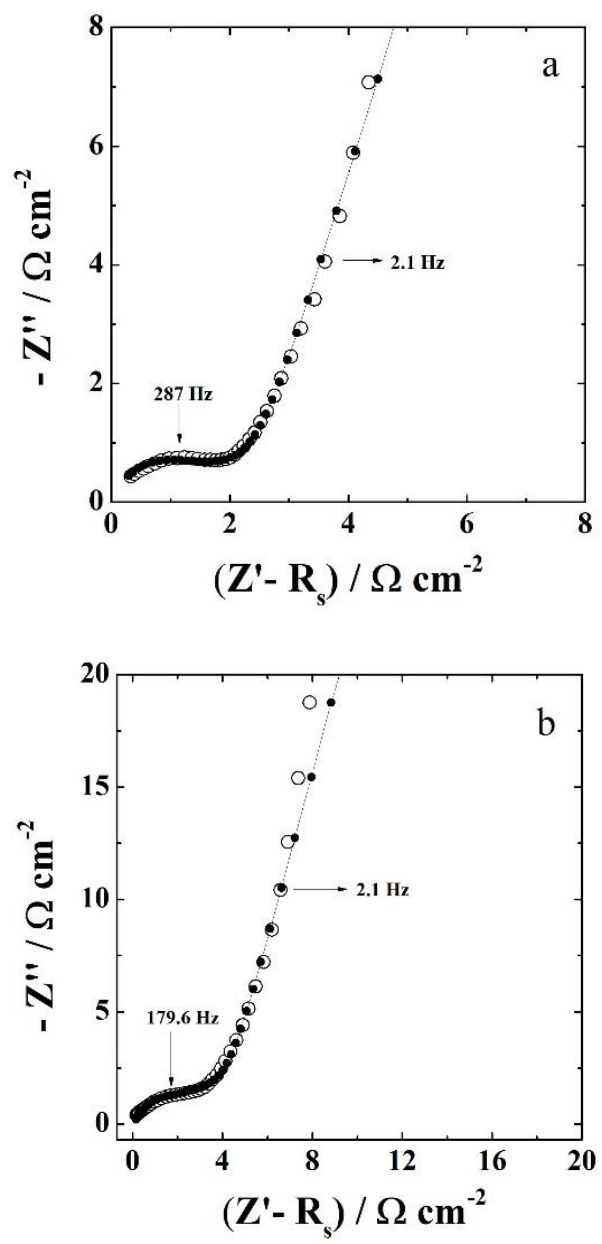

Figure 6 - Fitting (closed circle) and experimental (open circle) impedance data for proton electroinsertion in the $\mathrm{PMo}_{12}$ electrode: (a) at $\mathrm{pH}=2(\mathrm{E}=0.2 \mathrm{~V})$ and $(\mathrm{b})$ at $\mathrm{pH}=5.8(\mathrm{E}=-0.1$ $\mathrm{V}) . \mathrm{m}=0.1 \mathrm{mg}$.

To investigate the positive electrode for acid-base machine, we performed electrochemical measurements for NiHCF. Figure $7 \mathrm{a}$ corresponds to the cyclic voltammograms recorded in $\mathrm{K}_{2} \mathrm{SO}_{4} 20 \mathrm{mM}\left(\right.$ at $\mathrm{pH}=2$ ) and $\mathrm{K}_{2} \mathrm{SO}_{4} 25 \mathrm{mM}($ at $\mathrm{pH}=5.8)$ at 1 $\mathrm{mV} \mathrm{s}^{-1}$. We used $\mathrm{K}_{2} \mathrm{SO}_{4} 20 \mathrm{mM}$ electrolytic solution to decrease the ohmic drop and to avoid proton electroinsertion [13]. We increased the $\mathrm{K}_{2} \mathrm{SO}_{4}$ concentration from 20 to $25 \mathrm{mM}$ to simulate acid solution neutralization with $\mathrm{KOH}$ addition. However, if we wish to increase energy harvesting, we can simulate neutralization with addition of $\mathrm{KOH}$ and excess potassium salt (for instance, by using preconcentrated seawater to treat or to dilute wastewater and by 
using saline solution feedback resulting from the neutralization reaction). Hence, we also performed cyclic voltammetry experiments in electrolytic solutions containing $\mathrm{K}_{2} \mathrm{SO}_{4} 0.25 \mathrm{M}$ at $\mathrm{pH}=5.8$ (Figure 7a). The voltammetric peaks shift to more positive potentials as a function of the potassium ion concentration, indicating that these ions preferentially participate in the charge compensation mechanism. The average of the peak potentials associated with the redox pair shifts from $0.41 \mathrm{~V}$ to $0.49 \mathrm{~V}$ as the potassium ion concentration changes from 40 $\mathrm{mM}$ to $0.5 \mathrm{M}$. On the other hand, the peak potentials (shown in Figure $7 \mathrm{~b}$ ) do not change when the potassium ion concentration remains constant $(40 \mathrm{mM})$ and the $\mathrm{pH}$ changes from 2.0 to 5.8 , which demonstrates minimum or no proton participation in the charge compensation mechanism.
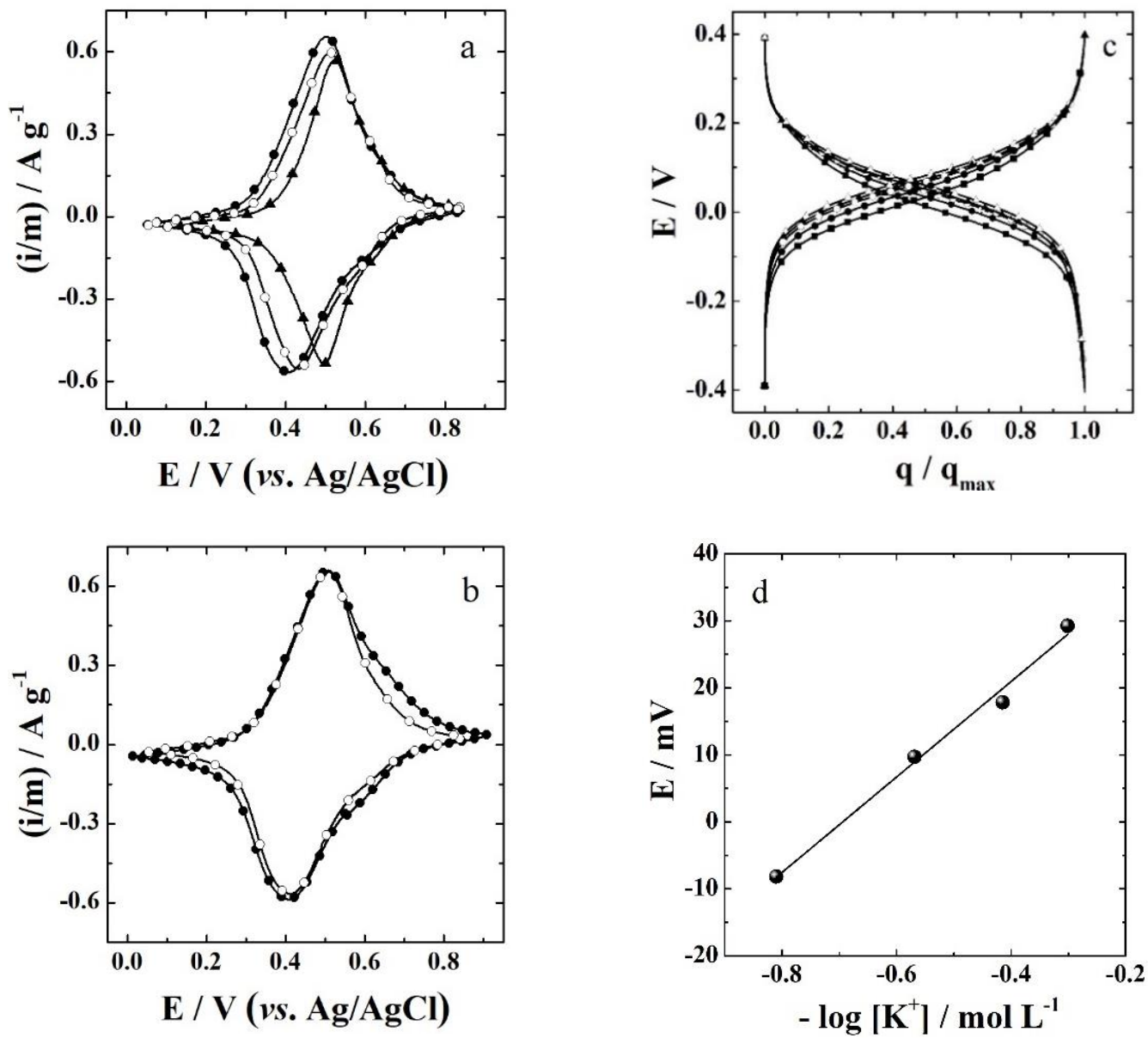

Figure 7 - Cyclic voltammograms recorded for NiHCF in electrolytic solution containing 
potassium ions at (a) (-○一) $40 \mathrm{mM}(\mathrm{pH}=2.0),(-\circ-) 50 \mathrm{mM}(\mathrm{pH}=5.8)$, and $(-\mathbf{\Lambda}-)$ $0.5 \mathrm{M}(\mathrm{pH}=5.8)$; and (b) (—○一) $40 \mathrm{mM}(\mathrm{pH}=2.0)$ and $(\longrightarrow-) 40 \mathrm{mM}(\mathrm{pH}=5.8) . \mathrm{m}=$ $0.32 \mathrm{mg} . v=1 \mathrm{mVs}^{-1}$. (c) Electroinsertion/electrodeinsertion curves for potassium ions at $(-\bullet-) 155 \mathrm{mM},(-\circ-) 270 \mathrm{mM},(-\mathbf{\Delta}-) 385 \mathrm{mM}$, and $(-\Delta-) 0.5 \mathrm{M}$ at $\mathrm{pH}=5.8$ and $10 \mu \mathrm{A}\left(31.3 \mathrm{~mA} \mathrm{~g}^{-1}\right) .(\mathrm{d})$ Average between the plateau potentials associated with the oxidation and reduction processes (at $\mathrm{q} / \mathrm{q}_{\max }=0.5$ ) as a function of the logarithm of the potassium ion concentration.

Figure $7 \mathrm{c}$ depicts the electroinsertion/electrodeinsertion curves for the NiHCF electrode at $10 \mu \mathrm{A} \cdot \mathrm{cm}^{-2}$ by using several potassium ion concentrations and $\mathrm{pH}=5.8$. In this case, we plotted the potential as a function of the charge normalized by the maximum charge $\left(\mathrm{q}_{\max }\right)$. Figure $7 \mathrm{~d}$, obtained at a normalized charge of 0.5 , presents changes in the plateau potential as a function of the logarithm of potassium ion concentration. The slope of these curves corresponds to $71.2 \mathrm{mV}$ per logarithm unit, which suggests that potassium ion participates in the charge compensation process, in agreement with Nernst's equation. Nevertheless, small proton insertion in the NiHCF electrode in the acid solution is not a hindrance for the acid-base machine proposed here because only potassium ion deinsertion has to occur in this medium.

Figure $8 \mathrm{a}$ corresponds to the NiHCF electrode electroinsertion/electrodeinsertion curves recorded for potassium ions at $40 \mathrm{mM}$ and $\mathrm{pH}=2$ and under currents ranging from 10 to $200 \mu \mathrm{A}$. In these conditions, if we consider the electroactive material mass, the NiHCF specific capacity is $51.2 \mathrm{mAh} \mathrm{g}^{-1}$ at $10 \mu \mathrm{A}\left(31.3 \mathrm{~mA} \mathrm{~g}^{-1}\right)$ and decreases to $40.2 \mathrm{mAh} \mathrm{g}^{-1}$ at 200 $\mu \mathrm{A}\left(625 \mathrm{~mA} \mathrm{~g}^{-1}\right)$. These specific capacity values are lower as compared to literature data [13]. Y. Cui et al. [8] observed specific capacities varying from 50 to $65 \mathrm{mAh} / \mathrm{g}$ for this Prussian Blue analogue during sodium and potassium ion cycling. Probably, effects associated with the 
particle distribution, electrolytic solution $\mathrm{pH}$, and current collector can be associated with lower specific capacities than those expected for these insertion electrodes.

Figure 8 also depicts the potassium ion electroinsertion/electrodeinsertion curves for potassium ions at (b) $50 \mathrm{mM}$ and (c) $0.5 \mathrm{M}$ at $\mathrm{pH}=5.8$. The specific capacity changes from $50 \mathrm{mAh} \mathrm{g}^{-1}$ at $10 \mu \mathrm{A}\left(31.3 \mathrm{~mA} \mathrm{~g}^{-1}\right)$ to $40 \mathrm{mAh} \mathrm{g}^{-1}$ at $200 \mu \mathrm{A}\left(625 \mathrm{~mA} \mathrm{~g}^{-1}\right)$ for potassium ions at $50 \mathrm{mM}$, whereas the specific capacity changes from $48 \mathrm{mAh} \mathrm{g}^{-1}\left(31.3 \mathrm{~mA} \mathrm{~g}^{-1}\right)$ to $35.7 \mathrm{mAh}$ $\mathrm{g}^{-1}\left(625 \mathrm{~mA} \mathrm{~g}^{-1}\right)$ for potassium ions at $0.5 \mathrm{M}$. The overpotential is significant for high current values. No parallel reactions take place in the selected potential window. Therefore, low currents must be applied to harvest energy from neutralization reactions for machine discharge at $\mathrm{pH}=5.8$.

Figure 9 presents the specific capacity as a function of the number of cycles in potassium ions at (a) $40 \mathrm{mM}$ and $\mathrm{pH}=2$ and (b) $0.5 \mathrm{M}$ and $\mathrm{pH}=5.8$, which changes from $51.2 \mathrm{mAh} \mathrm{g}^{-1}$ to $44.1 \mathrm{mAh} \mathrm{g}^{-1}$ and from $46.3 \mathrm{mAh} \mathrm{g}^{-1}$ to $34.2 \mathrm{mAh} \mathrm{g}^{-1}$, respectively. The coulombic efficiency remains virtually constant (about 96.5\%) during the cycles in potassium ions at $40 \mathrm{mM}$ and changes from $96.4 \%$ to $100.0 \%$ between the first and the twentieth cycle in potassium ions at $0.5 \mathrm{M}$. On the basis of these coulombic efficiency values, the self-discharge and/or charge trapping effects in this electrode are lower as compared to the $\mathrm{PMo}_{12}$ electrode (coulombic efficiency changed from $3.6 \%$ to almost null values of total injected charge as a function of the number of cycles). 


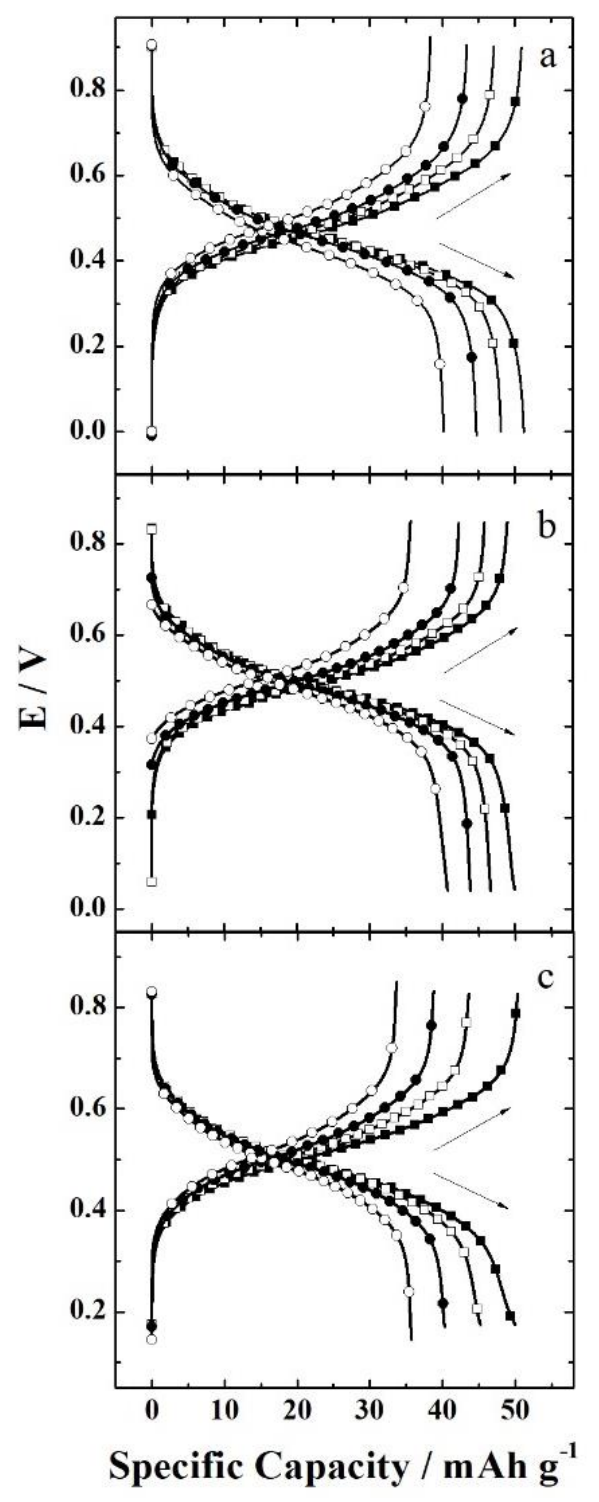

Figure 8 - Electroinsertion and electrodeinsertion curves for the NiHCF electrode at ( $\square-$ ) $31.3 \mathrm{~mA} \mathrm{~g}^{-1}(10 \mu \mathrm{A}),(-\square-) 62.5 \mathrm{~mA} \mathrm{~g}^{-1}(20 \mu \mathrm{A}),(-\bullet-) 156.3 \mathrm{~mA} \mathrm{~g}^{-1}(50 \mu \mathrm{A})$, and (—o—) $625 \mathrm{~mA} \mathrm{~g}^{-1}(200 \mu \mathrm{A})$ for potassium ions at (a) $40 \mathrm{mM}$ and $\mathrm{pH}=2$, (b) $50 \mathrm{mM}$ and $\mathrm{pH}=5.8$, and (c) $0.5 \mathrm{M}$ and $\mathrm{pH}=5.8 . \mathrm{m}=0.32 \mathrm{mg}$. 


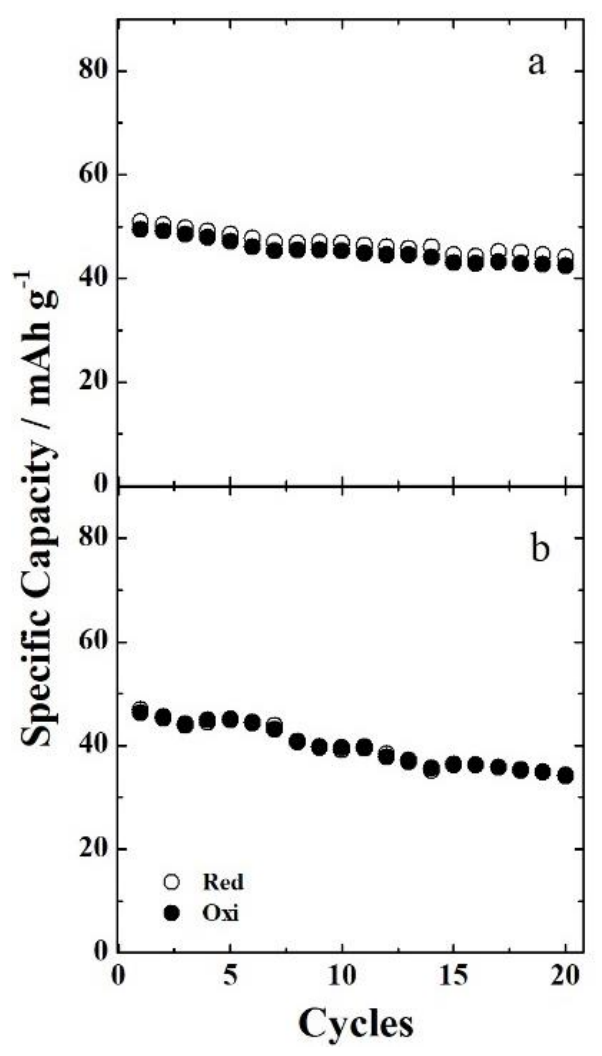

Figure 9 - Cyclability in potassium ions at: (a) $40 \mathrm{mM}$ and $\mathrm{pH}=2$; (b) $0.5 \mathrm{M}$ and $\mathrm{pH}=6 . \mathrm{i} / \mathrm{m}$ $=33.3 \mathrm{~mA} \mathrm{~g}^{-1}$ and $\mathrm{m}=0.3 \mathrm{mg}$.

On the basis of Figure 10a-b, the NiHCF electrode consists of agglomerated spherical particles with diameters close to $150 \mathrm{~nm}$, which partially cover the carbon cloth carbon fiber surface. Like the $\mathrm{PMo}_{12}$ electrode, the NiHCF electrode consists of a rough material comprised of voids. Therefore, the porous electrode model can also help to investigate ion and electronic transport, as mentioned above. 

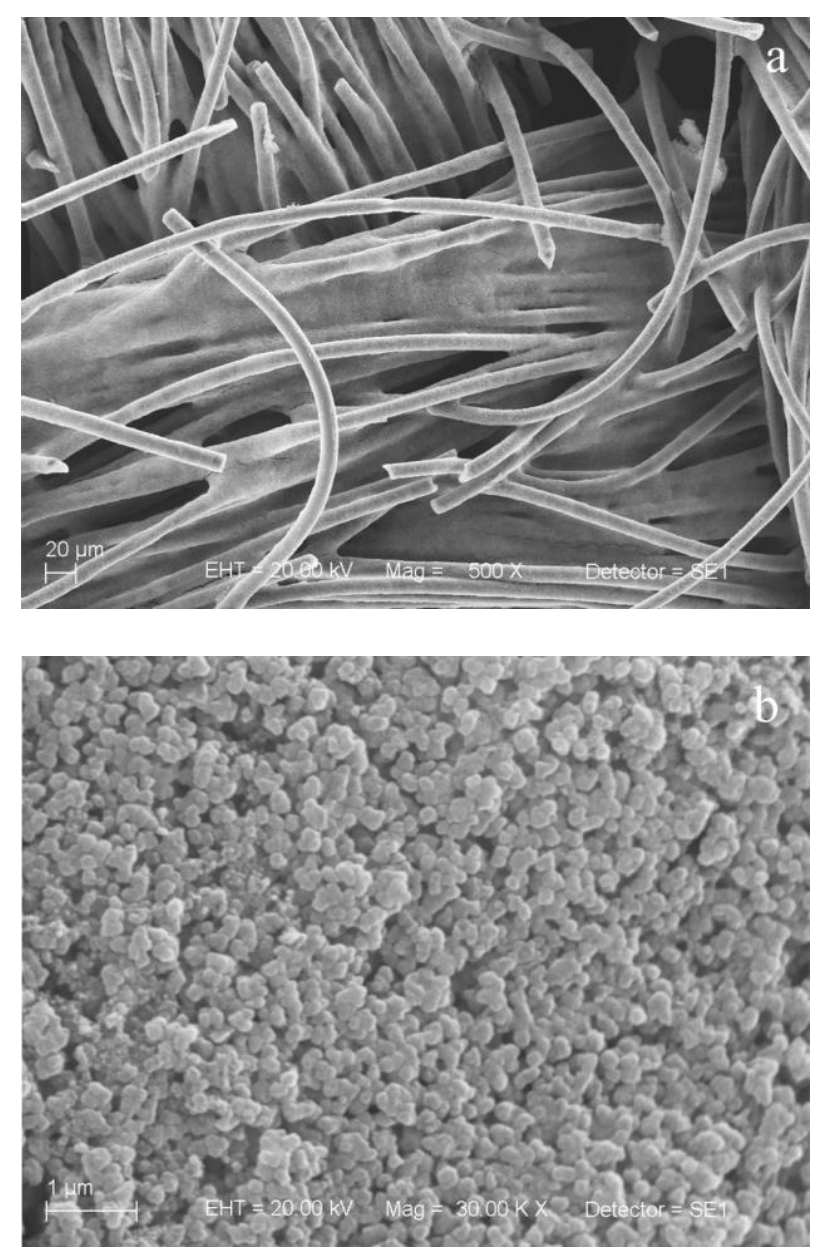

Figure 10 -SEM images of the NiHCF electrodes at (a) low and (b) high magnification.

Figure 11 illustrates the electrochemical impedance diagrams obtained for the NiHCF electrode at $0.45 \mathrm{~V}$ (for potassium ions at $40 \mathrm{mM}$ and $\mathrm{pH}=2$ ) and at $0.52 \mathrm{~V}$ (for potassium ions at $0.5 \mathrm{M}$ and $\mathrm{pH}=5.8$ ). We used Equation 9 to fit the experimental impedance data. The $\mathrm{x}_{1}$ values are $8 \mathrm{k} \Omega \mathrm{cm}^{-1}$ and $9 \mathrm{k} \Omega \mathrm{cm}^{-1}$ when the potassium ion concentration changes from 40 $\mathrm{mM}$ to $0.5 \mathrm{M}$, respectively. The $\mathrm{r}_{2}$ values vary from $95 \mathrm{k} \Omega \mathrm{cm}^{-1}$ to $45 \mathrm{k} \Omega \mathrm{cm}^{-1}$. Table 2 summarizes all the values of the parameters used in the fitting. These values suggest that potassium ion and electron mobility do not change significantly. Hence, similar current density values can be used during the charge (in acid medium) and discharge (in neutral or less acid medium) steps of the acid-base machine, to minimize the energy loss associated with high 
overpotentials.
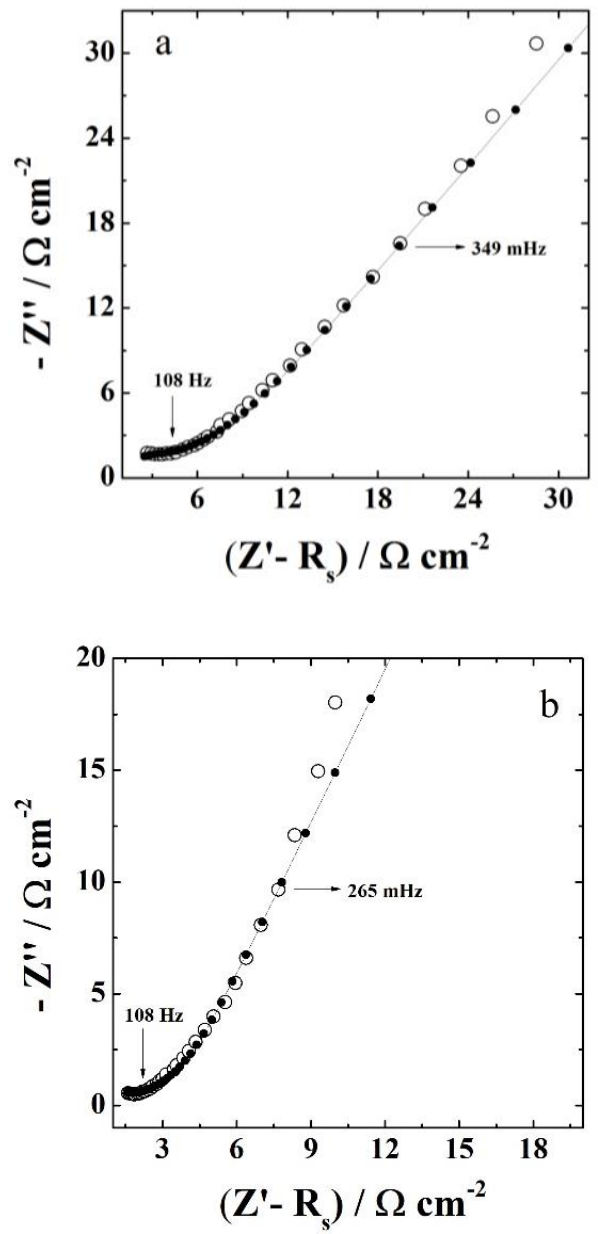

Figure 11 - Fitting (closed circle) and experimental (open circle) impedance data for potassium ion electroinsertion in the NiHCF electrode for potassium ions at (a) $40 \mathrm{mM}$ and $\mathrm{pH}=2, \mathrm{E}=0.45 \mathrm{~V}$ and (b) $0.5 \mathrm{M}$ and $\mathrm{pH}=5.8, \mathrm{E}=0.52 \mathrm{~V} . \mathrm{m}=0.32 \mathrm{mg}$.

Table 2 - Parameters obtained from fitting of the NiHCF electrode electrochemical impedance diagrams.

\begin{tabular}{cccccccccc}
\hline$\left[\mathrm{K}^{+}\right] / \mathrm{mM}(\mathrm{E} / \mathrm{V})$ & $\mathrm{R}_{\mathrm{s}}$ & $\mathrm{x}_{1}$ & $\mathrm{r}_{2}$ & $\omega_{\mathrm{m}}$ & $\mathrm{L}$ & $\mathrm{q}_{3}$ & $\mathrm{p}$ & $\beta$ & error \\
& $\Omega$ & $\mathrm{k} \Omega \mathrm{cm}^{-1}$ & $\mathrm{k} \Omega \mathrm{cm}^{-1}$ & $\mathrm{~Hz}$ & $\mu \mathrm{m}$ & $\mathrm{F} \mathrm{s}^{\beta-1} \mathrm{~cm}^{-}$ & & & $\%$ \\
& & & & & & 1 & & & \\
\hline $40(0.45)$ & 99.7 & 8 & 95 & 3500 & 200 & 155 & 0.98 & 0.57 & 0.25 \\
\hline
\end{tabular}




\begin{tabular}{llllllllll}
\hline $0.5(0.52)$ & 22.5 & 9 & 45 & 3000 & 200 & 318 & 0.98 & 0.74 & 0.65 \\
\hline
\end{tabular}

Using the parameters chosen for higher energy harvesting, we simulated $\mathrm{H}_{2} \mathrm{SO}_{4}$ solution neutralization with $\mathrm{KOH}$ in an acid-base machine. Figure 12a illustrates the charge (potassium ions at $40 \mathrm{mM}$ and $\mathrm{pH}=2$ ) and discharge (potassium ions at $50 \mathrm{mM}$ and $\mathrm{pH}=5.8$ ) curves for a full cell consisting of $\mathrm{PMo}_{12}$ and $\mathrm{NiHCF}$ as negative and positive electrodes, respectively. The area between these charge/discharge curves refers to the energy harvested after the electrochemical cycle and corresponds to $20.1 \mathrm{~kJ}\left(20.1 \mathrm{~kJ} \mathrm{~cm}^{-2}\right.$ and $\left.6.7 \mathrm{~W} \mathrm{~cm}^{-2}\right)$ per mol of electroinserted ions for this acid-base machine.

Considering that changes in potassium ion concentration enables energy harvesting, we also simulated acid solution neutralization with addition of $\mathrm{KOH}$ and a salt solution in the acid-base machine. Figure $12 \mathrm{~b}$ shows the charge (potassium ions at $40 \mathrm{mM}$ and $\mathrm{pH}=2$ ) and discharge (potassium ions at $0.5 \mathrm{M}$ and $\mathrm{pH}=5.8$ ) curves for the full cell. The harvested energy was $26.3 \mathrm{~kJ}\left(26.3 \mathrm{~kJ} \mathrm{~cm}^{-2}\right.$ and $\left.8.8 \mathrm{~W} \mathrm{~cm}^{-2}\right)$ per mol of electroinserted ions. Figure $12 \mathrm{c}$ depicts the harvested energy as a function of the number of cycles in potassium ions at $40 \mathrm{mM}$ and $\mathrm{pH}=2$ and in potassium ions at $0.5 \mathrm{M}$ and $\mathrm{pH}=5.8$, which went from $26.3 \mathrm{~kJ} \mathrm{~mol}^{-1}$ to $23.9 \mathrm{~kJ} \mathrm{~mol}^{-1}$.

The value of energy harvested per mol of charge is higher than the value obtained for blue-energy devices like CAPMIX (1.8 kJ per mol of charge) and Mixing Entropy Batteries $(12.3 \mathrm{~kJ}$ per mol of charge) $[3,5]$. Although the values recorded here are low as compared to other batteries, non-harnessed energy during neutralization reactions can be harvested and be high enough to stimulate wastewater treatment. To harvest a greater amount of energy, we could harness the energy associated with neutralization enthalpy, and the discharge process could be performed in an adiabatic step after neutralization. Thus, the acid-base machine would harvest energy from change in proton and potassium ion activity and would work as a 
thermal machine. Other materials should also be tested to maximize energy conversion, encourage wastewater treatment, and contribute to sustainable growth.
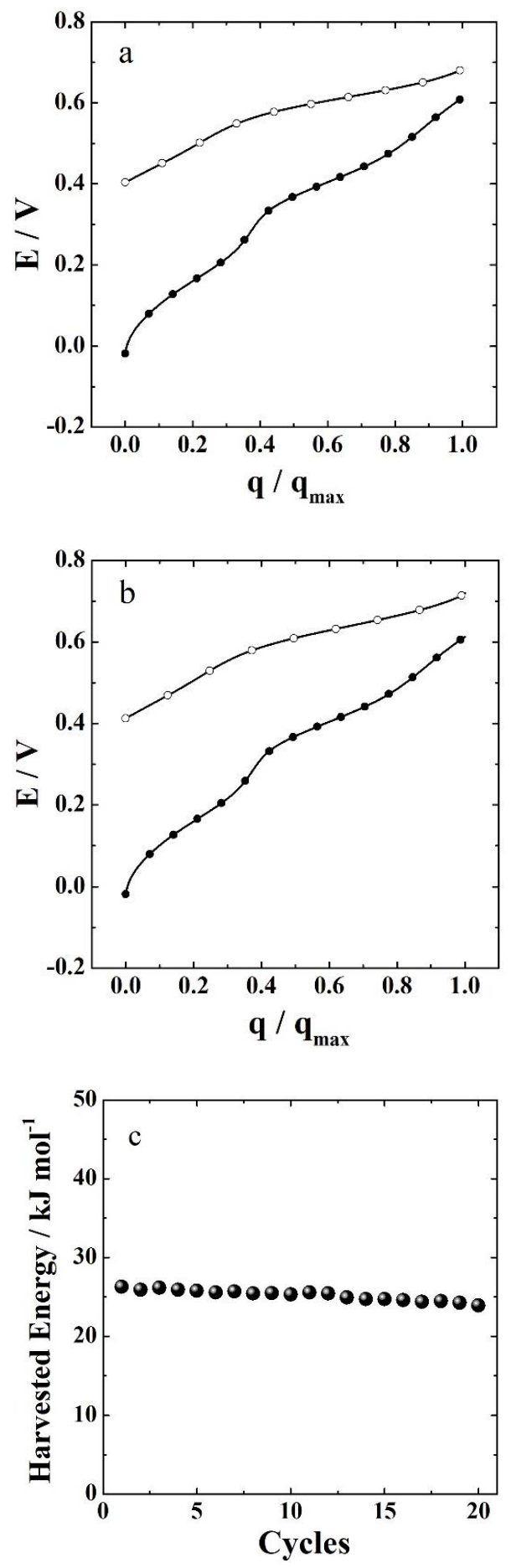

Figure 12 - Electrochemical cycle for the acid-base machine at $\mathrm{j}=10 \mu \mathrm{A} \mathrm{cm}{ }^{-2}$. Charge curve in $\mathrm{K}_{2} \mathrm{SO}_{4} 20 \mathrm{mM}$ and $\mathrm{pH}=2$; discharge curve in (a) $\mathrm{K}_{2} \mathrm{SO}_{4} 25 \mathrm{mM}$ and b) $\mathrm{K}_{2} \mathrm{SO}_{4} 0.25 \mathrm{M}$ and 
$\mathrm{pH}=5.8 . \mathrm{j}=10 \mu \mathrm{A} \mathrm{cm}^{-2}$.

\section{CONCLUSIONS}

This work has explored modified electrodes consisting of phosphomolybdic acid $\left(\mathrm{PMo}_{12}\right)$ as the negative electrode and nickel hexacyanoferrate (NiHCF) as the positive electrode in acid-base machines to harvest energy from entropy changes associated with proton and potassium ion concentration variation after base is added to an acid solution. Proton and potassium ion electroinsertion in $\mathrm{PMo}_{12}$ and $\mathrm{NiHCF}$, respectively, allows energy conversion after the electrochemical cycle. The electrodes have low practical irreversibility as attested by data in the time and frequency domains. We have also investigated the electrochemical response of these electrodes under several current densities as well as at different ion concentrations and as a function of the number of charge/discharge cycles. In addition, we have applied low current density for charge/discharge steps to maximize energy harvesting from neutralization. Potassium ion electroinsertion in neutral medium with high salt concentration enhances energy harvesting, which can be achieved by saline solution feedback resulting from neutralization. The energy harvested by these machines corresponds to $26.3 \mathrm{~kJ}$ per mol of electroinserted ions for the first cycle and to $23.9 \mathrm{~kJ}$ per mol of electroinserted ions for the twentieth cycle. Although several parameters must be improved to enable the practical use of these machines in wastewater treatment, this work demonstrates that these machines are viable for energy harvesting during wastewater treatment, thereby contributing to sustainable growth.

\section{ACKNOWLEDGMENTS}

We are grateful to FAPESP (Projects 2015/16867-9 and 2015/17628-8) for financial support. Partial funding from AGAUR (Generalitat de Catalunya) through project NESTOR 
(2014_SGR_1505) and MINECO (NaCarFLOW). (Grant MAT2015-68394-R,

MINECO/FEDER) is also acknowledged. ICN2 acknowledges support of the Spanish MINECO through the Severo Ochoa Centers of Excellence Program under Grant SEV-20130295.

\section{REFERENCES}

[1] T. Facci, W.J.A.S. Gomes, B. Bravin, D.M. Araújo, F. Huguenin, Proton Electroinsertion in Self-Assembled Materials for Neutralization Pseudocapacitors, Langmuir : the ACS journal of surfaces and colloids, 30 (2014) 426-431.

[2] W.J.A.S. Gomes, C. de Oliveira, F. Huguenin, Energy Harvesting by Nickel Prussian Blue Analogue Electrode in Neutralization and Mixing Entropy Batteries, Langmuir : the ACS journal of surfaces and colloids, 31 (2015) 8710-8717.

[3] D. Brogioli, Extracting Renewable Energy from a Salinity Difference Using a Capacitor, Physical Review Letters, 103 (2009) 058501.

[4] D. Brogioli, R. Zhao, P.M. Biesheuvel, A prototype cell for extracting energy from a water salinity difference by means of double layer expansion in nanoporous carbon electrodes, Energy \& Environmental Science, 4 (2011) 772-777.

[5] F. La Mantia, M. Pasta, H.D. Deshazer, B.E. Logan, Y. Cui, Batteries for Efficient Energy Extraction from a Water Salinity Difference, Nano Letters, 11 (2011) 1810-1813.

[6] V. Ruiz, J. Suárez-Guevara, P. Gomez-Romero, Hybrid electrodes based on polyoxometalate-carbon materials for electrochemical supercapacitors, Electrochemistry Communications, 24 (2012) 35-38.

[7] M. Sadakane, E. Steckhan, Electrochemical Properties of Polyoxometalates as Electrocatalysts, Chem. Rev., 98 (1998) 219-238.

[8] C.D. Wessells, M.T. McDowell, S.V. Peddada, M. Pasta, R.A. Huggins, Y. Cui, Tunable Reaction Potentials in Open Framework Nanoparticle Battery Electrodes for Grid-Scale Energy Storage, ACS Nano, 6 (2012) 1688-1694.

[9] Y. Yue, A.J. Binder, B. Guo, Z. Zhang, Z.A. Qiao, C. Tian, S. Dai, Mesoporous Prussian blue analogues: template-free synthesis and sodium-ion battery applications, Angew. Chem. Int. Ed. Engl., 53 (2014) 3134-3137.

[10] X. Wu, Y. Cao, X. Ai, J. Qian, H. Yang, A low-cost and environmentally benign aqueous rechargeable sodium-ion battery based on $\mathrm{NaTi} 2(\mathrm{PO} 4) 3-\mathrm{Na} 2 \mathrm{NiFe}(\mathrm{CN}) 6$ intercalation 
chemistry, Electrochemistry Communications, 31 (2013) 145-148.

[11] X.-y. Wu, M.-y. Sun, Y.-f. Shen, J.-f. Qian, Y.-1. Cao, X.-p. Ai, H.-X. Yang, Energetic Aqueous Rechargeable Sodium-Ion Battery Based on $\mathrm{Na} 2 \mathrm{CuFe}(\mathrm{CN}) 6-\mathrm{NaTi} 2(\mathrm{PO} 4) 3$ Intercalation Chemistry, ChemSusChem, 7 (2014) 407-411.

[12] P. Nie, L. Shen, H. Luo, B. Ding, G. Xu, J. Wang, X. Zhang, Prussian blue analogues: a new class of anode materials for lithium ion batteries, Journal of Materials Chemistry A, 2 (2014) 5852-5857.

[13] C.D. Wessells, S.V. Peddada, R.A. Huggins, Y. Cui, Nickel Hexacyanoferrate Nanoparticle Electrodes For Aqueous Sodium and Potassium Ion Batteries, Nano Letters, 11 (2011) 5421-5425.

[14] A. Bard, L. Faulkner, Electrochemical methods: Fundamentals and applications, John Wiley \& Sons, Inc., 2001.

[15] X. Wang, Z. Kang, E. Wang, C. Hu, Inorganic-organic hybrid polyoxometalate nanoparticle modified wax impregnated graphite electrode: preparation, electrochemistry and electrocatalysis, Journal of Electroanalytical Chemistry, 523 (2002) 142-149.

[16] D. Brogioli, R. Ziano, R.A. Rica, D. Salerno, F. Mantegazza, Capacitive mixing for the extraction of energy from salinity differences: Survey of experimental results and electrochemical models, Journal of Colloid and Interface Science, 407 (2013) 457-466.

[17] J. Bisquert, G. Garcia-Belmonte, F. Fabregat-Santiago, A. Compte, Anomalous transport effects in the impedance of porous film electrodes, Electrochemistry Communications, 1 (1999) 429-435.

[18] J. Bisquert, Influence of the boundaries in the impedance of porous film electrodes, Physical Chemistry Chemical Physics, 2 (2000) 4185-4192. 